\title{
CRISE ECONÔMICA E CRISE DO DIREITO: A INEFICÁCIA DOS DIREITOS HUMANOS E O MODELO DE DESENVOLVIMENTO
}

\author{
ECONOMIC CRISIS AND THE CRISIS OF THE LAW: THE INEFFICIENCY OF HUMAN RIGHTS AND \\ THE DEVELOPMENT MODEL
}

Eduardo C. B. Bittar"

\begin{abstract}
Resumo
A proposta deste artigo é a de investigar o estado atual da crise econômica global, correlacionando-a com os desafios mais presentes e atuais no campo dos direitos humanos e da democracia na realidade brasileira contemporânea. Para isso, recorrese a uma releitura crítica do modelo econômico predominante, dando-se ênfase à necessidade de revisão da vida moderna.

Palavras-chave: Crise econômica. Direitos Humanos. Democracia.
\end{abstract}

\begin{abstract}
The proposals of this article is to investigate the actual economics global crises, looking the actual devices in human rights and democracy, specially in the brazilian reality. In this sense, the article makes a critical lecture of the economic model that imposes revisions in the modern life;
\end{abstract}

Keywords: Economical crises. Human Rights. Democracy.

1. O modelo de desenvolvimento e a crise de ideologia

O centro de forças da ideologia do neoliberalismo estava fincado na idéia de que o Estado deve ser diminuído, e seu inchaço, sua burocracia, sua morosidade, substituídos pela eficiência, pela simplicidade e pela lucratividade operosa de mercado.' $\mathrm{O}$ Direito era visto como um empecilho, a ser superado, para que os canais da livre economia pudessem circular. Por isso, o espírito de enxugamento é que torna a atividade do Estado uma atividade reduzida a um minimalismo que afeta diretamente a lógica do Estado prestacional, reduzindo-se a sua faceta a formas de atuação mais concretamente voltadas para a lógica do Estado-repressor. Na euforia ideológica de seu início, o neoliberalismo

\footnotetext{
Livre-Docente e Doutor, Professor Associado do Departamento de Filosofia e Teoria Greral do Direito da Faculdade de Direito da Universidade de São Paulo, nos cursos de graduação e pós-graduação. Professor e pesquisador do Mestrado em Direitos Humanos do UniFIEO.

Presidente da Associação Nacional de Direitos Humanos (ANDHEP/ NEV-USP). Pesquisador-Sênior do Núcleo de Estudos da Violência da USP. Coordenador do Grupo de Pesquisa "Democracia, Justiça e Direitos Humanos: estudos de Escola de Frankfurt", junto ao NEV-USP.b

Pesquisador N-2 de Produtividade do CNPQ.

"O neoliberalismo também procurava reduzir o porte do aparelho do Estado e desregular todos os mercados, principalmente, os financeiros" (PEREIRA, Luiz Carlos Bresser. A crise financeira global e depois: um novo capitalismo? Novos Estudos, São Paulo, n. 86, p. 51-72, 2010. p. 55).
} 
apregoa a diminuição da ação do Estado em diversos campos, antes considerados essenciais para a vida social, o que se tornaria um ingrediente de aceleração da entrega de mercado, de alavancagem da economia real, de multiplicação de oportunidades e postos de trabalho, logo impactados pela soberania do ego descentrado do mercado livre global. ${ }^{2}$

No entanto, a crise econômica colhe o mercado em sua plena atividade, causando efeitos inúmeros. A crise impõe um stop a esta forma de operar da máquina do capital, que, atualmente, ainda se encontra em processo de recuperação. O que há para celebrar, após este processo? A morte de muitos dos direitos, a perda de garantias de Estado, a inoperância do constitucionalismo social, o enfraquecimento da consciência crítica na educação, a desarticulação das mobilizações sociais, a moleza dos padrões legais, a tendência social e institucional à práticas de exceção, a perda de referenciais para os sujeitos, a falta de padrões morais, a descrença na legislação como parâmetro, a desilusão quanto às perspectivas da organização de lutas emancipatórias para o futuro? Quando se trata de celebrar, se trata de festejar o banquete ao qual 3/4 do globo não podem participar, ou 9/10 das populações das nações não puderam acessar.

O otimismo gerado pela inovação tecnológica e pelas mudanças dos padrões de produção gerou, sem dúvida, um entusiasmo ímpar nos mercados. Um aquecimento da dinâmica da trocas globais ainda tornou mais profusa a onda de avanços de mercado. Por isso, celebrou-se com otimismo a vinda do novo contexto de desenvolvimento do sistema econômico capitalista. Na outra ponta, no âmbito da política, a perda da oposição e do sentido da oposição política dentro da modernidade, fator que, inclusive, gera uma grande anomia ideológica para as esquerdas em todo o mundo, aumenta a crença, que se torna quase-generalizada, de que o fim da história havia chegado. O Muro de Berlim divide esta história. Por isso, a celebração tinha a ver muito com a condição políticoeconômica da expansão dos mercados nas fronteiras dos processos de globalização, e, neste sentido, a carroagem do neoliberalismo parecia incontrolável, e, dentro dela, o festim da abundância, do regozijo e da farra financeira. A financeirização da economia, ${ }^{3}$ na feliz expressão de Bresser-Pereira, e o conjunto de práticas de economia irreal, artificial,

2 "Com a globalização da competição, a história acaba mudando radicalmente de sentido: em vez de pretender, ainda que em princípio, inspirar-se em ideais transcendentes, o progresso ou, melhor dizendo, o movimento das sociedades tende a ser apenas o resultado mecânico da livre concorrência entre seus diferentes componentes" (FERRY, Luc. Diante da crise: materiais para uma política de civilização. Relatório ao primeiro-ministro. Tradução Karina Jannini. Rio de Janeiro: Difel, 2010. p. 23).

3 "...resumirei a grande mudança dos mercados financeiros mundiais que ocorreu após o fim do sistema de Bretton Woods em 1971 e a associarei à financeirização e à hegemonia de uma ideologia reacionária, o neoliberalismo. A financeirização será aqui entendida como um arranjo financeiro distorcido, baseado na criação de riqueza financeira artificial, ou seja, riqueza financeira destigada da riqueza real ou da produção de bens e serviços" (PEREIRA, Luiz Carlos Bresser. A crise financeira global e depois: um novo capitalismo? Novos Estudos, São Paulo, n. 86, p. 51-72, 2010. p. 52). 
inclusive a bolha especulativa e as crenças sobre o crédito, na análise de Luc Ferry, ${ }^{4} \mathrm{e}$ isto tudo em detrimento da economia real, de produção e comércio, compõem o quadro deste processo de multiplicação de ilusões globais que se seguiram a esta onda.

Se a crise é um elemento constante no modo de operar do capitalismo, ela não há de ser vista como algo novo em sua história interna. Se esta questão parece bastante clara aos olhos dos analistas, sabe-se, também, que este modelo que imperou nas últimas duas ou três décadas, traria em breve suas conseqüências, e que elas poderiam ter sido evitadas, ${ }^{5}$ e junto com elas, os desempregos em massa, as instabilidades econômicas de economias inteiras, e o soterramento de bilhões de dólares em empresas desestabilizadas pela crise, dinheiro este cujo emprego seria muito necessário em capítulos tantos outros na distribuição, por exemplo, de direitos sociais. Seu caráter de exagero, de hipertrofia anômica dos mercados, de desregulação, de abatimento de toda forma de lei, provoca efeitos os mais notórios, a galope de um processo que se desenvolve com a cadência do desenvolvimento centrado em especulação, e não em economia real, e gera a volúpia insaciável pelo crescimento enfurecido e pela lógica de resultados. ${ }^{6}$

Este capítulo da história recente do capitalismo, e suas fragilidades constitutivas, ${ }^{7}$ já teve os seus efeitos mais notórios descerrados pela crítica à sociedade do consumo, ${ }^{8}$ à forma tax free de operar do capitalismo global, ao modo de operar a mecânica financista dos mercados globais, a perceber-se pelas negativas conseqüências sociais que provoca. ${ }^{9} \mathrm{O}$ esgotamento do modelo acumulador, e sua revisão necessária, se tornaram o

$4 \quad$ "O capitalismo está em crise, e esta, como mostramos, longe de ser anedótica e passageira, é essencial e estrutural, portanto, sem solução previsível a curto ou a médio prazos. A verdade é que já não podemos viver no mesmo modelo de desenvolvimento da década de 1960. Doravante, isso é impossível tanto no plano econômico quanto no ecológico e até moral" (FERRY, Luc. Diante da crise: materiais para uma política de civilização. Relatório ao primeiro-ministro. Tradução Karina Jannini. Rio de Janeiro: Difel, 2010. p. 109).

5 "As crises financeiras ocorreram no passado e voltarão a ocorrer no futuro, mas uma crise econômica tão profunda como a atual poderia ter sido evitada" (PEREIRA, Luiz Carlos Bresser. A crise financeira global e depois: um novo capitalismo? Novos Estudos, São Paulo, n. 86, p. 51-72, 2010. p. 59).

6 "A crise global de 2008 começou como costumam começar as crises financeiras em países ricos e foi causada pela desregulação dos mercados financeiros e pela especulação selvagem que essa desregulação permitiu" (PEREIRA, Luiz Carlos Bresser. A crise financeira global e depois: um novo capitalismo? Novos Estudos, São Paulo, n. 86, p. 51-72, 2010. p. 52).

7 "Tratava-se de um desequilíbrio em um minúsculo setor que, em tese, não deveria ter causado tamanha crise, mas o fez porque nos anos anteriores o sistema financeiro internacional fora tão intimamente integrado em um esquema de operações financeiras securitizadas que era essencialmente frágil, principalmente porque as inovações e a especulação financeiras tornaram o sistema financeiro como um todo altamente arriscado" (PEREIRA, Luiz Carlos Bresser. A crise financeira global e depois: um novo capitalismo? Novos Estudos, São Paulo, n. 86, p. 51-72, 2010. p. 53).

8 BAUMAN, Zygmunt. La globalización: consecuencias humanas. México: Fondo de Cultura Económica, 2001. p. 50 e ss.

9 "As conseqüências sociais desse processo só podem ser funestas. Afinal, desmentida a Lei de interdição, nega-se a alteridade - bem como a Alteridade -, não se reconhecendo mais a falta que identifica e motiva os laços que unem os sujeitos. E, isso ocorre, se o sujeito crê na sua totalidade, os demais já não são seus semelhantes, tratando-se de meros objetos postos à sua disposição" (COSTA, Domingos Barroso da. A crise 
mote dos tempos de crise. O que a idéia de desenvolvimento aí contida significava era um processo de cadenciamento de resultados financeiros, descolados da realidade, e que se construíam como tabelas imaginárias de projeções que se multiplicam independentemente de conseqüências para com os atores econômicos. Sem alicerces reais, a crise parecia até mesmo previsível, pois não há suporte concreto para a manutenção de um status de desenvolvimento a patamares tão elevados e fictícios.

Mais do que simplesmente aplacar a crise, matéria que se tornou ocupação de economistas e de políticos, de empresários e do sistema bancário-financeiro, é necessário caminhar adiante dos fatores endogênicos desse processo. Isso significa que a crise precisa ser superada não pela maquiagem de seus fatores superficiais, mas por uma revisão de seu modelo central. A partir da crise da 'verdade neoliberal', nas palavras de Luc Ferry, “... será preciso procurar outras que se inscrevam no mesmo espírito, pois, por certo, trata-se de uma mudança de direção e até mesmo de civilização, na medida em que toda a nossa análise repousa na idéia de que a civilização do consumo está em crise estrutural durável e de que é realmente necessário mudar de modelo de desenvolvimento" ${ }^{10}$ Aqui a expressão utilizada pelo autor aponta para a necessidade de mudar "o modelo de desenvolvimento" e isto é importante de ser grifado.

Essa grave expressão aponta para a necessidade de uma revisão mais profunda dos paradigmas que orientam a civilização, centrada, atualmente, basicamente, no consumo, no individualismo, e nos traços de uma cultura social narcisista. Nesse sentido, a crise assume um papel muito interessante, como oportunidade, no sentido de uma oportunidade de revisão. A crise ganha a qualidade de um problema político, moral e civilizatório, para além de seus limites financeiros e econômicos. Não sendo uma catástrofe em si, até mesmo porque o capitalismo tem tido elasticidade para se dobrar às mais terríveis crises econômicas, pode-se ler a crise de outra forma, ou seja, “...para o conjunto da sociedade, ela pode até ser uma oportunidade para abrir os olhos" 11

Neste sentido, a tarefa da reflexão crítica passa a ser a de concentrar seus esforços na reconstrução do cenário de transcendência das formas de operar da política e da economia que geram injustiça, desigualdade, miséria e robustecem a opulência, o individualismo, os privilégios e a ganância especulativa. Neste sentido, várias perdas havidas no interior de conquistas modernas, têm de ser recompostas. Ainda assim, atualmente, são poucas as alternativas concretas que se pronunciam, a identificar o cenário

do supereu e o caráter criminógeno da sociedade de consumo. Curitiba: Juruá, 2009. p. 128).

10 FERRY, Luc. Diante da crise: materiais para uma política de civilização. Relatório ao primeiro-ministro. Tradução Karina Jannini. Rio de Janeiro: Difel, 2010. p. 62.

1 Id. Ibid, p. 113. 
de perspectiva aberta após a crise. Esta se soma a um conjunto de outras tantas questões estudadas como efeitos da sociedade em contexto pós-moderno. ${ }^{12}$

\section{Crise da Lei, crise de ideologia e crise de modernidade}

A atual crise não se construiu do nada. Ela se conecta a um conjunto de crises da vida contemporânea. E o mais particular desses processos, é que, muitas vezes, os efeitos de processos de transformação sociais são sempre muito imprevisíveis. A passagem da modernidade à pós-modernidade, mediada por Maio de 68, traz consigo uma série de efeitos, entre eles, a desestabilização de paradigmas arraigados, muitos dos quais herdados da modernidade. Há, nisto, avanços e retrocessos. Há avanços palpáveis no plano do reconhecimento de minorias, no aumento da tolerância das famílias, na mudança de padrões autoritários de organização da relação pai-filho, entre outros. No entanto, entre os retrocessos, estão aqueles fatores que tornaram imprevisíveis que certas categorias de desmanche se espalhassem na definição da condição social atual. $\mathrm{Na}$ avaliação, ainda que conservadora de Luc Ferry, a partir de Maio de 68, “...era preciso que os valores e as autoridades tradicionais fossem desconstruídos pelos boêmios para que pudéssemos entrar na era do grande consumo, sem a qual o capitalismo globalizado simplesmente não seria possível. Com efeito, para que a renovação incessante dos valores da moda e do consumo triunfe para o grande benefício daqueles que lançam novos produtos, é necessário que os ideais tradicionais da moral, do patriotismo e da religião deixem de constituir um obstáculo para eles e lhes cedam o papel principal na estruturação da vida tanto individual quanto coletiva" 13

Um pouco mais adiante, Ferry ainda afirma: “...por trás da desconstrução das tradições, havia o surgimento do capitalismo globalizado: ou, para parodiar uma fórmula célebre de maio de 68 , sob os paralelepípedos, não havia a praia, mas a globalização liberal" ${ }^{14}$ A forte acusação aí contida revela uma visão de Maio de 68 um pouco heterodoxa, na medida em que rotula os movimentos de 68, a partir de seu fracasso, aliados ao sucesso posterior do neoliberalismo. Por isso, sobram os restos de pequenas emancipações locais a se conciliarem com a totalidade continuada do sistema do capitalismo que se tornava global. Considerando sua elasticidade, sua eficiência, e sua forma de operar que engloba tudo a partir da idéia de liberdade, torna-se fácil perceber que Maio de 68 foi engolida pela renovação do capitalismo dos anos 70 e 80 , do contrário, teríamos de concluir que os

12 A respeito, vide BITTAR, Eduardo C. B. O direito na pós-modernidade e reflexões frankfurtianas. 2. ed. Rio de Janeiro: Forense Universitária, 2009. p. 25 e ss.

13 FERRY, Luc. Diante da crise: materiais para uma política de civilização. Relatório ao primeiro-ministro. Tradução Karina Jannini. Rio de Janeiro: Difel, 2010. p. 34-35.

14 FERRY, Luc. Diante da crise: materiais para uma política de civilização. Relatório ao primeiro-ministro. Tradução Karina Jannini. Rio de Janeiro: Difel, 2010. p. 39. 
protestos de Maio de 68 eram estágios avançados de barricadas em prol do neoliberalismo, o que não pareceria nada correto do ponto de vista hermenêutico.

Ainda assim, a hipervalorização da riqueza, o materialismo desenfreado, a sede por inovação tecnológica, a distração provocada por inúmeros fatores próprios da sociedade da informação, vão se tornando experiências que se acumulam para gerar uma relativização em campos estratégicos e necessários para a vida social. ${ }^{15}$ Entre esses fatores, está a visão ideológica da lei, ou seja, como se enxerga a importância social da lei e dos códigos de processamento normativo do convívio, e, por isso, dos limites. Uma vez que Maio de 68 protestava contra os limites ("É proibido proibir!"), tornouse fácil para a recuperação do capitalismo, em sua nova fase, conquistar a juventude propondo o deslimite, bem como, avançando na corrosão da lei, que agora soava como um imperativo conservador a ter de ser superado. A era do imediatismo, do individualismo, do consumismo, do gozo, que destrona o pai, desmoraliza o supereu, e constrói o deslimite, carecia de uma contestação tão radical, tão firmemente estabelecida, quanto o conjunto dos excessos de radicalismos contidos nos protestos de Maio de $68 .{ }^{16} \mathrm{Com}$ isso, a roupagem das lutas sociais das décadas anteriores se dissolveram com uma rapidez tão assustadora, que suas conquistas jamais pareceram ter antes existido. Daí, a administração de uma condição social, política, cultura e econômica, pós-moderna, na qual a violência impera. ${ }^{17}$

Fato é que as últimas décadas permitiram uma experiência curiosa de transformações e aceleração das condições de vida. Nessa perspectiva, inúmeros fenômenos se processaram, entre eles o desmonte do Estado. O Estado se viu, claramente, ameaçado, em sua forma de atuação, e, especialmente, dentro da lógica do pós-guerra, de Estado de Bem-Estar Social, lateralizado, em nome de uma nova ideologia que

15 "Interessante observar que a Pós-modernidade, seus relativismos quanto a valores éticos ou morais, e sua destacada ênfase na riqueza, em última análise, no consumo que a representa, em muito se identifica com a pré-modernidade, o que explica o rápido e cômodo ajuste da meta neoliberal de globalização no Brasil. Em conseqüência disso, verifica-se a progressiva decadência dos valores modernos que começavam a se difundir no país - devido é recente industrialização, como dito, o que viabiliza a emersão dos propósitos que marcaram nosso processo de colonização predatória, como a negação da lei enquanto limite geral e a sede por vantagens e privilégios a qualquer custo." (COSTA, Domingos Barroso da. A crise do supereu e o caráter criminógeno da sociedade de consumo. Curitiba: Juruá, 2009. p. 22).

16 "Portanto, era preciso que a visão tradicional do mundo fosse desconstruída em todas as suas peças para que, finalmente livres dos tempos idos que freiam o consumo, pudéssemos nos entregar a ele sem contenções... pelo menos, é claro, no limite do nosso poder de comprar!" (FERRY, Luc. Diante da crise: materiais para uma política de civilização. Relatório ao primeiro-ministro. Tradução Karina Jannini. Rio de Janeiro: Difel, 2010. p. 35).

17 "Cenário e condições adequadas para o avanço da violência e da criminalidade que assola o país - com destaque para a que visa ganhos materiais -, em especial, a partir do final da década de 80 do século passado. Roubos, latrocínios, furtos, corrupção, assim como toda sorte de condutas que gravitam em torno do tráfico de drogas, tornaram-se normalizadas em nosso quotidiano, motivando intensos debates acerca do tema, ao qual se confere um trato que nem sempre prima pela crítica ou se desenvolve com ética" (COSTA, Domingos Barroso da. A crise do supereu e o caráter criminógeno da sociedade de consumo. Curitiba: Juruá, 2009. p. 22). 
predominava, e que descerrava a sociedade para fazer dela o repasto das novas promessas de engorda social. No entanto, no lugar da engorda generalizada, e da melhor distribuição, o que os mercados conseguiram provar foi a sua incapacidade de prover a sociedade de justiça. Mais gravemente, a sensação de desordem social, de anomia, de falta de confiança, geraram a consolidação de um espírito de convívio social sem barreiras e sem leis.

O desprezo pela lei, o desgaste da tutela social do Estado e a idéia de que as instituições são desnecessárias são traços desse disfarçado anarquismo social - em verdade, autoritário, pois subverte a regra para impor a sua - criado à carreira do neoliberalismo. ${ }^{18}$ O problema é que, após o fim de sua hegemonia, nem uma coisa e nem outra restam como referenciais; existe uma orfandade insuspeita na órbita da vida contemporânea, e ela pode ser apreendida nas formas de violência que se processam atualmente.

Da mesma forma como empresas sólidas - ou aparentemente sólidas - se desmancharam no auge da crise, a hegemonia do modelo neoliberal se desfez como um castelo de cartas soprado pelo vento. O que se vive hoje, pois, é um pouco a sensação de ressaca após a festa, após a celebração. Muita dor de cabeça e pouco o que fazer, além de se arrepender pelos exageros cometidos. A história do século XX é um horizonte de irritação desse processo, pois demonstra que os excessos, em todos os sentidos, foram muitos.

Uma pergunta que está no ar, e que não deixa de ressoar, é esta que se faz, dentro do sistema e fora do sistema capitalista. Nas palavras de Bresser-Pereira: "Teremos, então, um novo capitalismo?" ${ }^{19}$ È este tipo de pergunta que incita à necessidade de busca de novos referenciais, para o exercício de novas e criativas formas de fomento à construção de idéias que alicercem e estruturem a vida econômica social. Ainda: "O neoliberalismo acaba de ser derrotado; outros regimes de verdade terão que ser criticados e derrotados por novas idéias e atos, por movimentos sociais e pelo protesto ativo dos pobres e impotentes, por políticos e intelectuais que não se limitem a repetir slogans. Com isso, o progresso ocorrerá, ainda que lento, contraditório e sempre surpreendente por ser imprevisível" 20

18 "A hegemonia neoliberal nos Estados Unidos não causou apenas instabilidade financeira, menores taxas de crescimento e maior desigualdade econômica. Também implicou um processo generalizado de erosão da confiança social que é, provavelmente, o traço mais decisivo de uma sociedade sólida e coesa. Quando uma sociedade perde a confiança em suas instituições e na principal delas, o Estado, ou o governo, trata-se de um sintoma de uma doença social e política" (PEREIRA, Luiz Carlos Bresser. A crise financeira global e depois: um novo capitalismo? Novos Estudos, São Paulo, n. 86, p. 51-72, 2010. p. 64).

19 PEREIRA, Luiz Carlos Bresser. A crise financeira global e depois: um novo capitalismo? Novos Estudos, São Paulo, n. 86, p. 51-72, 2010. p. 71.

20 PEREIRA, Luiz Carlos Bresser. A crise financeira global e depois: um novo capitalismo? Novos Estudos, São Paulo, n. 86, p. 51-72, 2010. p. 72. 


\section{O estado atual da crise}

A crise recebe o nome de econômica ou financeira, conforme interpretações correntes, e debates entre especialistas. O intelectual francês, Luc Ferry, em seu texto Face à la crise, produzido em conjunto com o Conseil d'analyse de la société, e entregue como Relatório ao Primeiro-Ministro da França em 2009, afirma que não se trata de uma crise financeira, mas de uma crise mais profunda. Em suas palavras: "Contrariamente à opinião que hoje é apresentada um pouco em toda parte, em primeiro lugar a crise atual não é uma crise financeira, e sim uma crise econômica - o que, em certo sentido, é muito mais grave, mais profundo e implica respostas mais fundamentais" "21 Parece haver um consenso nas grandes discussões sobre o tema de que a era do capital livre e desimpedido se foi.

A crise econômica, em seu estado atual, abate o mundo desenvolvido ainda com grande virulência. Os protestos dos gregos, as instabilidades mais acentuadas em Portugal e na Espanha, a situação limítrofe de muitas economias pujantes, a descarga de tarefas sobre os centros financeiros de Frankfurt, são sinais de que a crise global de 2008 , atualmente, em julho de 2010 , ainda não foi superada. Por mais que se procure dela tratar como algo episódico, mais uma etapa, sem dúvida difícil, do capitalismo contemporâneo, ela representa mais um elemento a 'falar a língua' de uma crise mais generalizada, mais séria e mais profunda, do modelo de desenvolvimento financeirizador da última etapa do capitalismo, ${ }^{22} \mathrm{e}$, também, do conjunto dos paradigmas modernos. Para muitos economistas e analistas, como na opinião de Luiz Carlos Bresser-Pereira, trata-se mesmo da mais grave crise do capitalismo desde 1929, e, sem dúvida alguma, de um episódio de marcante significação para uma virada histórica do capitalismo. ${ }^{23}$

As interpretações dos economistas, e as evidências vindas dos mercados, não são de que esta crise seja tão passageira quanto se espera. ${ }^{24}$ Quase dois anos e meio

${ }^{21}$ FERRY, Luc. Diante da crise: materiais para uma política de civilização. Relatório ao primeiro-ministro. Tradução Karina Jannini. Rio de Janeiro: Difel, 2010. p. 09.

22 "Por meio de inovações financeiras arriscadas, o sistema financeiro como um todo, composto de bancos e investidores financeiros, pode criar riqueza fictícia e capturar uma maior fatia da renda nacional, ou da riqueza real" (PEREIRA, Luiz Carlos Bresser. A crise financeira global e depois: um novo capitalismo? Novos Estudos, São Paulo, n. 86, p. 51-72, 2010. p. 57).

23 "A crise bancária que teve início em 2007 e tornou-se uma crise global em 2008 provavelmente representará uma virada na história do capitalismo. Além de ser a crise econômica mais severa enfrentada pelas economias capitalistas desde 1929, é também uma crise social que, segundo previsões da Organização Internacional do Trabalho, elevou o número de desempregados de cerca de 20 milhões para 50 milhões ao fim de 2009." (PEREIRA, Luiz Carlos Bresser. A crise financeira global e depois: um novo capitalismo? Novos Estudos, São Paulo, n. 86, p. 51-72, 2010. p. 51).

24 "Essa crise não irá terminar em breve. A reação dos governos a ela em termos monetários e fiscais foi tão decisiva que ela não irá se transformar em depressão, mas levará tempo para se resolver por um motivo básico: as crises financeiras sempre decorrem de elevado endividamento ou alta alavancagem e da conseqüente perda de confiança por parte de credores" (PEREIRA, Luiz Carlos Bresser. A crise financeira global e depois: um novo capitalismo? Novos Estudos, São Paulo, n. 86, p. 51-72, 2010. p. 68). 
após o seu início nos EUA, agora no meio do ano de 2010 , a crise persiste, afetando o tecido econômico da Europa, em especial Grécia, Portugal e Espanha. Desesperança e falta de inventividade social são os testemunhos e os traços desse esgotamento. Nos registros históricos desse processo recente, o Caderno Economia do jornal O Estado de São Paulo, de 05 de fevereiro de 2010, registra na reportagem "Crise na Europa derruba mercados", noticia a percepção da continuidade da crise, ao apontar as baixas nas bolsas de valores nos seguintes quadros: $-5,94 \%$, Madrid; $-4,98 \%$, Lisboa; -4,73, São Paulo; -3,82, Buenos Aires; -3,45, Milão; -2,99\%, Nova York; -2,45, Frankfurt. Num período posterior, marcado por desemprego e grandes protestos, já em 07 de maio de 2010, o Caderno Dinheiro do jornal $A$ Folha de São Paulo, na reportagem intitulada "Crise na Grécia afeta real e derruba Bolsas" destaca o índice de $-9,26 \%$ na queda da bolsa americana, como um recorde em queda, a abalar o sistema financeiro americano e global. A tendência desse processo é o aumento global das diferenças de classes, e um maior acúmulo social de tensões decorrentes das desigualdades sociais, mesmo nos países mais ricos e desenvolvidos. ${ }^{25}$

Sinais vivos da oscilação de um mercado global, reciprocamente influente, altamente volátil, sensivelmente suscetível, e que tem de conviver com um ciclo de crise que custa a se retirar do cenário. Este cenário, por falta de alternativas, apesar de certas frágeis utopias comparecerem para afirmar que a morte das meta-narrativas não é ainda a morte de todas as utopias sociais, aponta para uma continuidade do modelo toyotista de produção, para a manutenção da forma globalizada de trocas internacionais, e para a continuidade do capitalismo centrado no conhecimento. ${ }^{26}$ Qualquer cenário de mudança do capitalismo, ou no capitalismo, far-se-á a partir de sua própria crise interna, e não pela contraposição a um outro modelo existente, o que demonstra o estado de apatia política e econômica globais.

4. A crise, a realidade brasileira e os Direitos Humanos: o contexto do $3^{\circ}$ PNDH

A questão de relevo que parece ser de todo significativa para as pesquisas brasileiras é aquela que se detém na percepção do estado atual da crise global, com foco na realidade brasileira. Extrair percepções do fenômeno, a partir da leitura de vozes estrangeiras e nacionais, já foi um exercício anteriormente feito, o que deixa como insumo

25 "...a desigualdade de renda nos países ricos provavelmente se intensificará, embora seu estágio de crescimento seja compatível com uma redução da desigualdade, na medida em que o progresso tecnológico é predominantemente poupador de capital, ou seja, reduz, os custos ou aumenta a produtividade do capital" (PEREIRA, Luiz Carlos Bresser. A crise financeira global e depois: um novo capitalismo? Novos Estudos, São Paulo, n. 86, p. 51-72, 2010. p. 69).

26 Cf. PEREIRA, Luiz Carlos Bresser. A crise financeira global e depois: um novo capitalismo? Novos Estudos, São Paulo, n. 86, p. 51-72, 2010. p. 68. 
a necessidade de ser exercitado um outro, a saber, o de reflexão em torno do impacto da crise econômica para o capitalismo brasileiro contemporâneo, bem como sobre o quanto ele afeta as políticas essenciais, os direitos humanos e, em especial, os direitos sociais, no país.

Se partirmos da leitura feita por Márcia Poole, Diretora-geral de comunicação da Anistia Internacional, pode-se constatar algo de interessante na composição desse quadro conjuntural. Ela afirma: "'O Brasil decolou', afirmou o influente semanário britânico The Economist, em novembro do ano passado. Coincidência ou não, o perfil do país só faz crescer" ${ }^{27}$ As publicações internacionais estão todas acirradas com a estabilidade econômica da moeda brasileira e com a capacidade de prosperidade de seu mercado consumidor. Mais ainda, a resistência do país aos efeitos da crise tem sido tão estarrecedora, que se torna um fenômeno comparável ao empréstimo que o Brasil fez ao FMI: "Essa agenda em sem dúvida, ambiciosa, mas não está fora do alcance do Brasil. Afinal de contas, quem teria apostado que, em 2009, o Brasil emprestaria dinheiro ao FMI?" 28

A estabilidade, para um país que viveu os anos 60, 70, 80 e 90 mergulhado em instabilidades políticas e econômicas, somente pode ser sinal de sua saúde política e econômica, ao entrar no século XXI. Nessa medida, estas parecem ser as medidas políticas ligadas ao neodesenvolvimentismo, indicando e percorrendo um caminho notório no sentido da proteção das economias emergentes. ${ }^{29}$ Isso tem representado, inclusive, um avanço no plano do combate à pobreza e às diferenças sociais, como os índices começam a reconhecer. Notícias também apontam neste sentido: "O percentual de pobres caiu de maneira sustentável no Brasil entre 2004 e 2008 e, mesmo com a crise financeira internacional, o movimento provavelmente não foi interrompido em 2009, de acordo com a economista Sonia Rocha, do Instituto de Estudos do Trabalho e Sociedade. Ela apresentou ontem, no $22^{\circ}$ Fórum Nacional, um estudo com base em dados da Pesquisa Nacional por Amostra de Domicílios do IBGE, que mostra que a proporção de pobres no país caiu de $33,2 \%$ para $22,9 \%$ no período pesquisado" ${ }^{30} \mathrm{Com}$ a melhoria das condições de vida da população, sem dúvida alguma, trata-se de uma oportunidade interessante e

27 POOLE, Márcia. Falta compromisso com direitos humanos. Folha de S. Paulo, São Paulo, 30 maio 2010. Tendências/ Debates, A 3.

28 POOLE, Márcia. Falta compromisso com direitos humanos. Folha de S. Paulo, São Paulo, 30 maio 2010. Tendências/ Debates, A 3.

29 "Os ricos ficarão menos ricos, mas permanecerão ricos, enquanto os pobres ficarão mais pobres; só os paises de rendimento intermediário dedicados à estratégia neodesenvolvimentista surgirão da crise mais fortes" (PEREIRA, Luiz Carlos Bresser. A crise financeira global e depois: um novo capitalismo? Novos Estudos, São Paulo, n. 86, p. 51-72, 2010. p. 70).

30 GÓIS, Antônio. Proporção de pobres cai para $23 \%$ no Brasil. Segundo estudo, percentual era de $33 \%$ há quatro anos; Sudeste está entre as regiões mais favorecidas. Folha de S. Paulo, São Paulo, 21 maio 2010. Dinheiro, B 10. 
estratégica para o Brasil se projetar como um ator global relevante, especialmente no plano internacional. Tudo isso tem sido, e deve ser motivo de otimismo, ainda que parcial.

Se o Brasil conseguiu blindar sua economia aos efeitos mais perversos da escalada da crise em todo o mundo, o tema da crise não se basta na questão financeira. Há muito o que ser feito, para que o país conquiste de fato a solidez de sua democracia, se o termo 'democracia' tiver que ser utilizado em seu sentido mais amplo e pleno. Notícias de mercado registram os paradoxos do desenvolvimento na região Nordeste do Brasil, indicando-se que o "Nordeste vive 'Chináfrica', com aceleração e gargalos" 31 E as notícias avançam para apontar que: "O mercado imobiliário e os negócios no Nordeste vivem uma explosão de preços e de atividade. Mas a infraestrutura que sustenta o atual ritmo 'chinês' pode ser definida como 'africana"" ${ }^{32}$ Essa reportagem, que traz evidências e preocupado do mercado, está atravessada por uma premissa anterior que vale a pena ser explorada. Apesar do boom imobiliário, há fortes carências primárias na região, que é a mais pobre do país.

Mas, antes disso, ela revela, com clareza, a face de dois Brasis convivendo lado a lado: o da explosão otimista da vitória sobre a crise (China), e a das carências elementares que são herdadas como saldo negativo de processos sociais anteriores (África). O Brasil do século XXI, diante dos passos não dados no século XX. Também, revela o Brasil que está diante de paradoxos e distâncias sociais tão perversos, onde as desigualdades permitem uma distância de classes sociais, padrões de consumo e condições de vida, cujas disparidades também permitem diferenciar o espetáculo econômico do crescimento chinês e as condições reais de vida e desenvolvimento africanas.

Enfim, tomado como metáfora, o trecho ilustra de que modo se dá o processo contemporâneo de desenvolvimento e superação da crise no país, talvez, aprofundando ainda mais as desigualdades que subsistem na base das graves distorções sociais brasileiras. Por isso, a advertência feita por Márcia Poole deve ser lida com atenção: "Se o Brasil age com desenvoltura cada vez maior nas questões econômicas ou de política internacional, existe uma área em que o país ainda está por demonstrar liderança - os direitos humanos" 33 É exatamente neste ponto que vale a pena parar a análise, para considerar o quanto o tema dos direitos humanos no Brasil é deficitário. O empreendimento de uma cultura dos direitos humanos implica na compreensão de que o respeito aos direitos, a realização da Constituição social, e o provimento cidadão nos direitos, são todos eles fatores de

31 CANZIAN, Fernando. Nordeste vive Chináfrica, com aceleração e gargalos. Folha de S. Paulo, São Paulo, 30 maio 2010. Mercado, B 1.

32 CANZIAN, Fernando. Nordeste vive Chináfrica, com aceleração e gargalos. Folha de S. Paulo, São Paulo, 30 maio 2010. Mercado, B 1.

33 POOLE, Márcia. Falta compromisso com direitos humanos. Folha de S. Paulo, São Paulo, 30 maio 2010. Tendências/ Debates, A 3. 
socialização indispensáveis, e, para isso, não é necessário seguir a lógica neoliberal, mas avançar no sentido de constituir nas políticas de Estado, formas avançadas de provimento do que é mais elementar e constitutivo à vida social, onde se encontram os direitos sociais.

Deve-se ressaltar que o $3^{\circ}$ Programa Nacional de Direitos Humanos, que propõe um aprofundamento e uma radicalização da democracia e dos direitos humanos no Brasil, aparece em dezembro de 2009, período em que a crise econômica demonstra grande força em todo o mundo. Percebe-se essa aparição como um fenômeno que revela a confiança de governo na maturidade da sociedade brasileira, do ponto de vista político, mas também de perceber aí um sintoma de que a segurança econômica é fundamental para a saúde da eficácia social dos direitos humanos; o Brasil se coloca numa vanguarda social, em que, avançando através do $3^{\circ}$. PNDH em temas cruciais da débil democracia nacional, talvez se possa ousar afirmar estar-se diante de um importante passo adiante dentro da história do país, e um sintoma de renovação que não se encontra em outras democracias contemporâneas. ${ }^{34}$

Ainda que o $3^{\circ}$. PNDH não seja um documento de pleno consenso nacional, e tenha nascido da atividade do Estado, em parceria com a sociedade civil, sua proposta é de grande valor paradigmático para a renovação do debate sobre direitos humanos no país. É nesse sentido que, ao lado do crescimento econômico, pode-se apostar no avanço no tratamento dos direitos humanos como uma estratégia importante de governo, mas sobretudo, como uma política permanente de Estado, a realizar plenamente as ambições de sustentabilidade econômica e de respeitabilidade internacional do país, perante outras nações. "Do mesmo modo, a voz do Brasil terá maior credibilidade se puder apontar para um quadro positivo com relação aos direitos humanos. As reformas, ainda que limitadas, na área da segurança pública, são um bom começo. Mas ainda restam muitos problemas graves, como as execuções extrajudiciais, a violência policial, as condições do sistema penitenciário e a impunidade dos que cometeram abusos contra os direitos humanos, inclusive durante a ditadura" 35

São Paulo, março de 2010.

${ }_{34}$ "Embora a transição para a democracia participativa e- um passo adiante- a democracia deliberativa ainda não esteja claramente em andamento, antevejo que a democracia continuará a progredir porque continuará a pressão dos trabalhadores e da classe média por maior participação pública" (PEREIRA, Luiz Carlos Bresser. A crise financeira global e depois: um novo capitalismo? Novos Estudos, São Paulo, n. 86, p. 51-72, 2010. p. 70).

35 POOLE, Márcia. Falta compromisso com direitos humanos. Folha de S. Paulo, São Paulo, 30 maio 2010. Tendências/ Debates, A 3. 


\section{Referências}

AZEVEDO, Maria Nazareth Farani. Os direitos humanos em tempos de crise. Folha de S. Paulo, São Paulo, 15 mar. 2009. A 3.

BARRETO, Vicente. Educação e violência: reflexões preliminares. Revista Brasileira de Filosofia, São Paulo, fasc. 165, p. 63-70, jan./mar. 1992.

BAUMAN, Zygmunt. Em busca da política. Tradução de Marcus Penchel. Rio de Janeiro: Jorge Zahar, 2000.

La globalización: consecuencias humanas. México: Fondo de Cultura Económica, 2001.

BERCOVICI, Gilberto; MASSONETO, Luís Fernando. A constituição dirigente invertida: a blindagem da Constituição Financeira e a Agonia da Constituição Econômica. Boletim de Ciências Econômicas, Coimbra, v. XLIX, p. 57-77, 2006.

BITTAR, Eduardo C. B. O direito na pós-modernidade e reflexões frankfurtianas. 2. ed. Rio de Janeiro: Forense Universitária, 2009.

PEREIRA, Luiz Carlos Bresser. A crise financeira global e depois: um novo capitalismo? Novos Estudos, São Paulo, n. 86, p. 51-72, mar. 2010.

CANZIAN, Fernando. Nordeste vive Chináfrica, com aceleração e gargalos. Folha de S. Paulo, 3. maio 2010. Mercado, B 1 .

COSTA, Domingos Barroso da. A crise do supereu e o caráter criminógeno da sociedade de consumo. Curitiba: Juruá, 2009.

FERRY, Luc. Diante da crise: materiais para uma política de civilização. Relatório ao primeiroministro. Tradução Karina Jannini. Rio de Janeiro: Difel, 2010.

HONNETH, Axel, O capitalismo como forma de vida fracassada: esboço sobre a teoria da sociedade de Adorno. Politica e trabalho: Revista de Ciências Sociais, n. 24, p. 09-26, abr. 2006. . Justiça e liberdade comunicativa: reflexões em conexão com Hegel. Revista Brasileira de Estudos Políticos, Belo Horizonte, n. 89, p. 101-120, jan./ jun. 2004.

Reificación: un estudio en la teoría del reconocimiento. Buenos Aires: Katz, 2007.

GÓIS, Antônio. Proporção de pobres cai para 23\% no Brasil. Segundo estudo, percentual era de 33\% há quatro anos; Sudeste está entre as regiões mais favorecidas. Folha de S. Paulo, 21 maio 2010. Dinheiro, B 10.

POOLE, Márcia. Falta compromisso com direitos humanos. Folha de S. Paulo, 30 maio 2010. Tendências/ Debates, A 3.

$3^{\circ}$ PROGRAMA NACIONAL DE DIREITOS HUMANOS. Secretaria Especial de Direitos Humanos. Brasília: Imprensa Oficial, 2009. 
ROUANET, Sergio Paulo. Mal-estar na modernidade. 2. ed. São Paulo: Companhia das Letras, 1993.

SAFATLE, Vladimir. Cinismo e falência da crítica. São Paulo: Boitempo, 2008. 